\section{Treinamento resistido reduz inflamação em músculo esquelético e melhora a sensibilidade à insulina periférica em ratos obesos induzidos por dieta hiperlipídica}

\author{
Resistive training reduces inflammation in skeletal \\ muscle and improves the peripheral insulin sensitivity \\ in obese rats induced by hyperlipidic diet
}

Ana Carolina Panveloski-Costa', Danilo Antônio Correa Pinto Júnior', Bruna Brasil Brandão', Rafael Junges Moreira',

Ubiratan Fabres Machado², Patrícia Monteiro Seraphim

\section{RESUMO}

Objetivo: Investigar em ratos obesos o efeito da prática de exercício resistido sobre a sensibilidade à insulina e sobre a expressão de citocinas pró-inflamatórias e de transportador de glicose em músculo solear. Materiais e métodos: Ratos Wistar alimentados com dieta hiperlipídica (grupos obesos) foram submetidos ao protocolo de exercício tipo jump squat. A sensibilidade à insulina e a expressão gênica de Tnf- $\alpha$, SOCS3 e GLUT4 foram comparadas entre os grupos obesos sedentários (OS) e exercitados (OE) e controles sedentários (CS) e exercitados (CE). Resultados: A sensibilidade à insulina estava reduzida no grupo OS e elevada no OE. Os conteúdos de RNAm deTnf- $\alpha$ e de SOCS3 estavam aumentados no músculo esquelético do grupo OS e reduzidos no OE. O conteúdo proteico e de RNAm de GLUT4 não diferiu entre os grupos. Conclusão: 0 exercício resistido reverte o quadro de resistência à insulina periférica e de inflamação no músculo esquelético de obesos induzidos por dieta. Arq Bras Endocrinol Metab. 2011;55(2):155-63

Descritores

Dieta hiperlipídica; exercício resistido; sensibilidade à insulina; GLUT4; Tnf- $\alpha$; SOCS3

\begin{abstract}
Objective: To determine if resistive exercise protocol can modulate Tnf- $\alpha$, SOCS3 and glucose transporter GLUT4 genes expression in skeletal muscle, and peripheral insulin sensitivity in obese rats induced by hyperlipidic diet. Materials and methods: Wistar obese rats induced by hyperlipidic diet were subjected a resistive exercise protocol as jump squat. Insulin sensitivity and mRNA content of Tnf- $\alpha$, SOCS3 and GLUT4 were assayed and compared among the groups: obese sedentary (OS) and exercised (OE), control sedentary (CS) and exercised (CE). Results: The mRNA content of Tnf- $\alpha$ and SOCS3 has increased in skeletal muscle from OS and has decreased in OE group. The protein and GLUT4 mRNA contents were correlated but they did not change among the groups. Peripheral insulin sensitivity has increased in the OE compared to OS group. Conclusion: The resistive exercise reverses the peripheral insulin resistance and the inflammatory state in skeletal muscle from diet-induced obese rats. Arq Bras Endocrinol Metab. 2011;55(2):155-63
\end{abstract}

\section{Keywords}

Hyperlipidic diet; resistive exercise; insulin sensitivity; GLUT4; Tnf- $\alpha$; SOCS3
${ }^{1}$ Departamento de Fisioterapia, Grupo de Pesquisa em Fisiologia Universidade Estadual Paulista Júlio de Mesquita Filho (Unesp), Campus Presidente Prudente, Presidente Prudente, SP, Brasil ${ }^{2}$ Departamento de Fisiologia e Biofísica, Instituto de Ciências Biomédicas, Universidade de São Paulo (USP), São Paulo, SP, Brasil

Correspondência para: Patrícia Monteiro Seraphim Departamento de Fisioterapia, Bloco III - FCT/Unesp

Rua Roberto Simonsen, 305 Centro Educacional 19060-900 - Presidente Prudente, SP, Brasil

patricia@fct.unesp.br

Recebido em 2/Set/2010 Aceito em 7/Fev/2011 


\section{INTRODUÇÃO}

$\mathrm{A}$ obesidade é considerada uma epidemia mundial presente em países desenvolvidos e em desenvolvimento. Embora os mecanismos precisos que correlacionam a obesidade com a resistência à insulina e diabetes melito tipo 2 ainda não estejam definidos, provavelmente se relacionam à produção de vários fatores derivados dos adipócitos que atuam no fígado, no músculo ou no próprio tecido adiposo, comprometendo a ação da insulina (1).

Em modelos de obesidade, a resistência à insulina está associada à redução da expressão de transportador de glicose (GLUT4) e/ou prejuízo na via de sinalização da insulina em músculo esquelético e tecido adiposo (2), o que está associado a um quadro de inflamação subclínica característico da obesidade, resultante da maior circulação de fatores pró-inflamatórios como o fator de necrose tumoral (Tnf- $\alpha$ ), interleucina-lb (IL$-1 b)$, entre outros (3).

A relação entre o aumento da expressão de Tnf- $\alpha$ e os prejuízos na sensibilidade à insulina no músculo esquelético já foi demonstrada em animais in vitro (4) e in vivo (5) e em humanos in vivo (6). O Tnf- $\alpha$ reduz a sinalização da insulina e promove fosforilação do substrato do receptor de insulina (IRS-1) em resíduos de serina e treonina, prejudicando a propagação do sinal da insulina para captação de glicose em tecidos insulino-dependentes (7).

Além disso, o aumento da expressão de Tnf- $\alpha$ pode levar à resistência à insulina por indução da expressão de proteína supressora de sinalização de citocinas (SOCS) (8). A proteína SOCS é induzida por diversas citocinas, em vários tecidos, de maneira tecido-específica e citocina-específica.

Embora a SOCS seja uma proteína originalmente pertencente à via de sinalização de citocinas, foi mostrado recentemente que ela também pertence ao circuito de sinalização da insulina (9). Quando expressa, a Socs3 localiza-se no citoplasma em condições basais. Após o tratamento com insulina, foi observado seu deslocamento para a membrana plasmática, onde pode interagir com o receptor da insulina, atuando negativamente na sinalização do hormônio (9).

$\mathrm{O}$ treinamento resistido (TR), assim como o treinamento aeróbio, também está associado à redução do risco de doenças relacionadas a baixo grau de inflamação, tais como aterosclerose, obesidade e resistência à insulina (10).
O regulamento de adaptação do músculo esquelético ao exercício resistido é orquestrado por uma complexa rede de cinases e fosfatases sujeitas a um elevado grau de regulação por retroalimentação, cruzamento de vias de sinalização e ativação transitória (11).

Em longo prazo, o TR pode diminuir os níveis basais de citocinas que desempenham papel negativo no metabolismo da glicose (12). No entanto, dados da literatura ainda não são conclusivos quanto ao efeito do exercício sobre as concentrações plasmáticas e musculoesqueléticas de citocinas (13).

A maioria dos relatos dos efeitos do exercício na modulação de citocinas são provenientes de estudos envolvendo treinamento aeróbio $(14,15)$. Em contraste, as provas sobre a relação entre exercício resistido e inflamação são mais limitadas (16). As respostas fisiológicas e o padrão de citocinas liberadas pelo músculo no exercício aeróbio são diferentes dos obtidos em exercício resistido (17).

A literatura aponta um efeito redutor na expressão de Tnf- $\alpha$ em tecido muscular esquelético em resposta aguda (18) ou crônica (19) à atividade física resistida. No entanto, os efeitos do TR no conteúdo de Tnf- $\alpha$ dependem do compartimento em que a mensuração é realizada: no plasma ou no tecido muscular (proteína ou expressão de RNAm) (20).

Relatos da literatura são controversos quanto ao efeito do TR sobre o Tnf- $\alpha$. Alguns estudos mostram ausência (21-23), outros, diminuição (19) ou aumento (24) na concentração plasmática e/ou expressão gênica dessa proteína.

No entanto, estudos que avaliem o efeito do TR na modulação de marcadores inflamatórios envolvidos no prejuízo da cascata de sinalização da insulina em tecido muscular esquelético são escassos na literatura. Nesse contexto, este estudo pretende identificar os efeitos que o exercício físico resistido exerce sobre a expressão de citocinas pró-inflamatórias em músculo esquelético solear envolvidas no prejuízo da sensibilidade à insulina decorrente da obesidade.

\section{MATERIAIS E MÉTODOS}

\section{Animais}

Ratos Wistar com 2 meses de idade (180-200 g), provenientes do Biotério Central da Unesp - Campus Botucatu, foram utilizados neste estudo. Os animais foram mantidos no biotério de experimentação na Unesp - 
Campus Presidente Prudente, sob condições padronizadas de temperatura $\left(22 \pm 2{ }^{\circ} \mathrm{C}\right)$ e ciclo claro/escuro (12/12 horas diárias).

Os procedimentos experimentais utilizados no presente estudo foram aprovados pelo Comitê de Ética em Experimentação Animal da Unesp - Campus Presidente Prudente, processo $n^{\circ} 15 / 2009$.

\section{Desenho experimental}

Os animais foram distribuídos em quatro grupos: controle sedentário (CS), controle exercitado $(\mathrm{CE})$, obeso sedentário $(\mathrm{OS})$ e obeso exercitado $(\mathrm{OE})$.

Os animais controles foram alimentados com ração-padrão (marca SUPRA LAB - Alisul Ind. Alimentos Ltda., São Leopoldo/RS; com composição de $25 \%$ de proteínas, $3 \%$ de lipídeos, $18 \%$ de fibras, $11 \%$ de material mineral, $2 \%$ de cálcio e $0,5 \%$ de fósforo) e água fornecida ad libitum. Os grupos OS e OE foram alimentados com uma dieta hiperlipídica adaptada de Lamas e cols. (2004), composta por: bacon, mortadela, salsicha, bolacha, refrigerante e ração-padrão, numa proporção de aproximadamente $2: 2: 2: 1: 1: 1$, respectivamente, numa composição de $28 \%$ de carboidratos, $13 \%$ de proteínas e 59\% de lipídeos, a partir do segundo mês de vida (25). $\mathrm{O}$ peso corpóreo (PC) dos animais foi registrado semanalmente.

Após dois meses de dieta hiperlipídica, com 4 meses de idade, os animais dos grupos exercitados (CE e $\mathrm{OE}$ ) foram submetidos a um protocolo de treinamento resistido. Os animais passaram por uma semana de adaptação antes do início do protocolo de treinamento resistido e os animais que resistiram à atividade foram distribuídos nos grupos sedentários (CS e OS). O treinamento resistido foi realizado seguindo o modelo de força proposto por Tetsuro Tamaki e cols. (26), com algumas adaptações. $\mathrm{O}$ aparelho foi projetado de maneira que o animal ficava imobilizado por um colete adaptado sobre uma plataforma metálica. A estimulação elétrica foi realizada utilizando clipe metálico que envolvia a extremidade da cauda do animal e estava ligado a um eletroestimulador do tipo Dualpex 961, da Quarker, calibrado pelo Inmetro (Instituto Nacional de Metrologia, Normalização e Qualidade Industrial). Os parâmetros utilizados foram: frequência de $1 \mathrm{~Hz}$, duração de 0,3 s com intervalo de $2 \mathrm{~s}$ entre cada estimulação elétrica, e a intensidade foi ajustada de maneira que o animal executasse o movimento, variando de 3 a $6 \mathrm{~mA}$. Esses parâmetros foram adotados por serem pulsos bidirecionais de média nula, não apresentando efeitos eletrolíticos, permitindo aplicações de longa duração sem risco de lesão dos tecidos.

Com essa estimulação, o rato realizou o movimento de extensão completa da pata (joelho e tornozelo), levantando uma carga que era posicionada na parte posterior do colete. Os animais realizaram três séries de 12 repetições, três vezes por semana, durante seis semanas. Foram realizadas três sessões de adaptação ao treinamento na primeira semana sem incremento de carga: uma, duas e três séries de 12 repetições do primeiro ao terceiro dia, respectivamente. Nas primeiras duas semanas, os animais realizaram o treinamento sem incremento de carga. A partir da terceira semana, uma carga equivalente a $50 \%$ do PC foi imposta até o final do protocolo de treinamento resistido. A carga foi ajustada semanalmente de acordo com as variações do PC.

\section{Teste de tolerância à insulina (ITT)}

Para a avaliação da sensibilidade à insulina, os animais foram submetidos ao teste de tolerância à insulina in vivo. Nesse teste foi administrada insulina na dose de $50 \mu \mathrm{U} / 100 \mathrm{~g}$ de peso corpóreo na veia peniana e foi analisada a concentração de glicose sérica em diferentes tempos de coleta de sangue ( 0 - tempo basal a 16 minutos) após a administração da insulina.

Esse teste foi realizado uma semana antes do sacrifício, sendo utilizados quatro ratos de cada grupo, os quais foram anestesiados com xilasina e quetamina $(0,3$ $\mathrm{mg} / \mathrm{kg}$ de peso corpóreo). A glicemia foi determinada por glicosímetro (Biocheck, Brasil).

\section{Coleta do material}

Após 24 horas da última sessão de treinamento, os animais foram submetidos a duas horas de jejum e foram sacrificados por meio de anestésico (mistura de xilasina e quetamina $-60 \mathrm{mg} / \mathrm{kg}$ do peso corporal de cada componente) por via intraperitoneal. Em seguida, foram retirados o músculo esquelético sóleo e o tecido adiposo branco periepididimal (TA).

\section{Quantificação do RNA}

O RNA total das amostras do músculo sóleo foi isolado com Brazol (LGCBio Biotecnologia, Brasil), seguindo as recomendações do fabricante. As concentrações de RNA foram determinadas pela absorbância a $260 \mathrm{~nm}$. A pureza do RNA foi determinada mediante o cálculo da relação de absorbância a 260 e $280 \mathrm{~nm}$, bem como por coloração por brometo de etídio. 
Para transcrição reversa, $5 \mu \mathrm{g}$ de RNA total foram submetidos às reação de transcrição reversa com primers randômicos para a síntese de uma fita de DNA complementar ao mRNA (cDNA). Posteriormente, foi realizada a amplificação dos fragmentos dos genes do GLUT4 (Slc2a4) (sense 5' - CCCCTCCAGGGCAAAGGAT 3', antisense: 5' - TCCTGGAGGGGAACAAGAA - 3'), da SOCS3 (sense: 5' - CCTTTGAGGTTCAGGAGCAG - 3'; antisense: 5' GTAGCCACGTTGGAGGAGAG 3') e do Tnf- $\alpha$ (sense: 5' - AAGATGTCTCAGGCCTCC - 3'; antisense: 5' - AGACAGCTTCCCAACGAT - 3') por meio da reação de polimerização em cadeia (PCR). Os produtos amplificados foram então submetidos à eletroforese em gel de agarose (EtBr) e visualizados com iluminação UV (Kodak Molecular Imaging Software Version 4.0, 2-User e Eletronic UV Transilluminator Ultra. Lum. Inc.). Para a análise densitométrica das bandas obtidas, foi utilizado o software Scion Image (Scion Corporation, Frederick, Maryland, USA), apropriado para esse fim. A expressão do RNAm para o gene GLUT4 foi normalizada pela expressão da beta-actina (Actb) (sense 5' - ATGAAGATCCTGACG AGCGTG - 3' e antisense 5' - CTTGCTGATCCACA TCTGCTGG - 3'), calculada pela razão dos valores densitométricos de cada amostra para o gene GLUT4 e o gene constitutivo.

\section{Quantificação de proteínas}

Para a técnica de Western Blotting, foi realizado o processo de obtenção da fração de membranas totais (MT). Para isso, o tecido muscular solear foi homogeneizado em tampão TRIS HCl $10 \mathrm{mM}$, EDTA $1 \mathrm{mM}$, sacarose $250 \mathrm{mM}, \mathrm{pH} 7,4$, usando-se Polytron PT 3000 Kinematica $^{\circledR}$ (Brinkman). Em seguida, foi submetido a uma centrifugação a $1.000 \mathrm{~g}$ durante 10 minutos, $4^{\circ} \mathrm{C}$. $\mathrm{O}$ sobrenadante foi guardado e o precipitado ressuspenso em mesmo tampão ( $1 / 3$ do volume inicial) e submetido novamente à centrifugação $(1.000 \mathrm{~g})$ por 10 minutos, a $4^{\circ} \mathrm{C}$. Os dois sobrenadantes foram somados e então submetidos à ultracentrifugação a $150.000 \mathrm{~g}$, durante 75 minutos, a $4^{\circ} \mathrm{C}$. O sedimento correspondente à fração de membranas totais (MT) foi ressuspenso em $600 \mu \mathrm{L}$ de tampão de homogeneização e estocado a $-20^{\circ} \mathrm{C}$ até a utilização.

A concentração de proteína total da fração de membranas totais foi avaliada por meio do método de Lowry. Após 30 minutos de incubação a $37^{\circ} \mathrm{C}$, a concentração de proteína foi avaliada por leitura em espectrofotômetro $(670 \mathrm{~nm})$, utilizando-se uma curva de calibra- ção de albumina bovina sérica (BSA) de 0,05 a $1,0 \mathrm{mg} / \mathrm{mL}$. Os valores de concentração proteica das amostras de fração de membranas totais foram aferidos nesta curva de calibração.

A detecção das quantidades de proteínas GLUT4 no músculo sóleo foi realizada utilizando-se eletroforese em gel de poliacrilamida, com a utilização de kit de quimiluminescência (ECL) para detecção das bandas. Resumidamente, o método consistiu em: quantidades iguais de proteínas foram solubilizadas em tampão de Laemmli, separadas de acordo com o peso molecular em SDS-PAGE (10\%) e então transferidas eletroforeticamente para membrana de nitrocelulose Hybond-C Super (GE Healthcare, Amersham Biosciences, UK). Após bloqueio com albumina sérica bovina em PBS a $8 \%$ durante 1 hora, as membranas foram incubadas com anticorpo antiGLUT4 (Chemicon) (diluição 1:3000 em PBS), durante 3 horas a $37^{\circ} \mathrm{C}$. Posteriormente, foi realizada uma incubação com os anticorpos secundários anti-IgG, marcados com peroxidase (HRP), diluídos em l:10.000, em solução bloqueadora BSA a $1 \%$, durante 1 hora. As membranas foram lavadas vigorosamente com tampão PBS e colocadas em contato com $3 \mathrm{~mL}$ de reagente de detecção ${ }^{\circ} 1$, acrescidos de $3 \mathrm{~mL}$ de reagente de detecção $n^{\circ} 2$ do kit ECLTM - Western Blotting Detection Reagents (GE Healthcare, Amersham Biosciences, UK) por 2 minutos e expostas a Hyperfilm $^{\circledast}$ (IGF - Corporation, New Jersey, USA) por períodos de 2, 4, 6 e 8 minutos, para detecção das bandas resultantes. As bandas identificadas na autorradiografia foram quantificadas por meio de densitometria óptica pelo programa Scion Image Software (ScionCorp, Frederick, MD). O anticorpo antiGLUT4 utilizado foi obtido na Chemicon International, Temecula, Califórnia.

\section{Análise estatística}

A avaliação estatística dos resultados foi realizada por meio do programa Instat versão 3.01. Os valores são expressos em média e erro-padrão da média (EPM). O teste Kolmogorov-Smirnov revelou que os resultados dos experimentos apresentam distribuição normal. A comparação entre os grupos foi realizada usando o teste ANOVA one-way com post-hoc de Tukey. As diferenças entre os grupos foram consideradas significantes quando o valor de $P$ foi menor que 0,05 .

\section{RESULTADOS}

Para induzir a obesidade nos animais, foi ofertada uma dieta hiperlipídica composta por alimentos hipercalóri- 
cos a partir do segundo mês de idade. A partir da terceira semana de oferta, observou-se aumento significante no peso corpóreo dos animais que receberam a dieta hiperlipídica (OS e OE), quando comparados aos animais que receberam dieta-padrão ( $\mathrm{CS}$ e $\mathrm{CE}$ ). $\mathrm{O}$ TR não influenciou no peso corpóreo dos animais que receberam dieta hiperlipídica ou padrão (Figura 1 ).

A tabela 1 ilustra as características de composição corporal dos animais. Os valores apresentados na segunda coluna mostram que os animais sedentários submetidos à dieta hiperlipídica (OS e $\mathrm{OE}$ ) apresentaram aumento estatisticamente significante na porcentagem de ganho de peso corpóreo ao longo do período de estudo, quando comparados aos grupos controles (CS e CE). No entanto, quando submetido ao protocolo de treinamento, o grupo $\mathrm{OE}$ apresentou redução nesse valor, comparado ao grupo OS, evidenciando a eficiência do treinamento resistido imposto. Além disso, verificou-se aumento expressivo da massa adiposa periepididimal nos animais submetidos à dieta hiperlipídica de $49 \%$ no grupo OS $(P<0,001)$ e de $42 \%$ no grupo OE $(P<0,01)$, quando comparados aos grupos controles CS e CE, respectivamente. No entanto, quando submetido ao treinamento resistido $(\mathrm{OE})$, o tecido adiposo periepididimal apresentou redução de $27 \%$ comparado ao grupo OS $(P<0,01)$. Os valores de peso relativo de massa muscular solear não apresentaram diferenças entre os grupos.

Em relação à sensibilidade à insulina, observou-se que os ratos submetidos à dieta hiperlipídica por um período de quatro meses apresentaram redução na constante de decaimento da glicose (kITT) calculada (Tabela 1). Em contrapartida, o treinamento resistido imposto aumentou a resposta ao estímulo da insulina, indicando maior capacidade de depuração de glicose durante o ITT nos animais do grupo OE, quando comparados aos animais do grupo OS $(P<0,01)$.

$\mathrm{Na}$ figura 2, são ilustrados os valores densitométricos em unidades arbitrárias (UA) referentes à expres- são de RNAm de GLUT4, Socs3 e Tnf- $\alpha$ no músculo sóleo. A dieta hiperlipídica causou aumento de $26 \%$ $(P<0,05)$ e de $33 \%(P<0,001)$ do conteúdo de RNAm de Socs3 e Tnf- $\alpha$, respectivamente, no grupo OS, quando comparado ao grupo CS. No entanto, quando submetidos ao treinamento resistido $(\mathrm{OE})$, houve redução de $22 \%$ tanto na expressão de RNAm de Socs3 $(P<0,05)$ quanto de Tnf- $\alpha(P<0,05)$ em relação ao grupo OS. O treinamento per se nos animais do grupo CE não alterou o conteúdo de RNAm desses genes em relação ao grupo CS. Embora não houvesse diferença estatística no conteúdo de RNAm do GLUT4, concomitantemente ao aumento na expressão de RNAm de Socs3 e Tnf- $\alpha$, o grupo sedentário submetido à dieta hiperlipídica (OS) apresentou redução de aproximadamente $28 \%$ no conteúdo de RNAm de GLUT4. Em contrapartida, os animais do grupo OE apresentaram

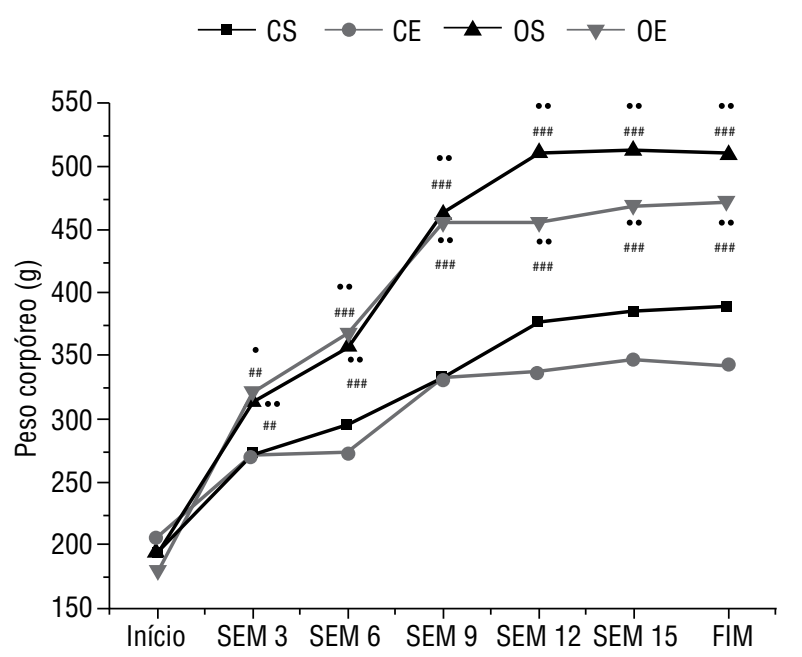

Figura 1. Gráfico representativo da evolução do peso corpóreo nos grupos controle sedentário (CS), controle exercitado (CE), obeso sedentário (OS) e obeso exercitado (OE). Valores expressos em gramas (g) como média \pm EPM ( $n=7$ a 10 animais por grupo). Na abscissa, 0 "início" representa 0 tempo inicial da oferta da dieta hiperlipídica. ${ }^{\star} P<0,01$ vs. CS; ${ }^{* *} P<0,001$ CS; \# $P<0,01$ vs. CE; \#\# $P<0,001$ vs. CE.

Tabela 1. Composição corporal e constante de decaimento da glicemia (kITT)

\begin{tabular}{llccc}
\hline Grupos & Peso corpóreo (\%) & Peso relativo do TA & Peso relativo do M. Sóleo & kITT \\
\hline CS & $192 \pm 7,54$ & $10,6 \pm 0,91\left(10^{-3}\right)$ & $0,46 \pm 0,02\left(10^{-3}\right)$ & $5,76 \pm 0,36$ \\
CE & $163 \pm 3,76$ & $8,79 \pm 0,67\left(10^{-3}\right)$ & $0,56 \pm 0,03\left(10^{-3}\right)$ & $6,63 \pm 0,45$ \\
OS & $283 \pm 12,0^{* * \# \#}$ & $20,83 \pm 0,17\left(10^{-3}\right)^{* * \#}$ & $0,44 \pm 0,59\left(10^{-3}\right)$ & $3,60 \pm 0,62^{*}$ \#\# \\
OE & $250 \pm 6,43^{* * \# \# \&}$ & $15,21 \pm 0,75\left(10^{-3}\right)^{* \# \&}$ & $0,48 \pm 0,21\left(10^{-3}\right)$ & $7,07 \pm 0,47^{\& \&}$ \\
\hline
\end{tabular}

Porcentagem de ganho do peso corpóreo ao longo do tratamento expresso em percentual (\% de peso corpóreo); peso relativo do tecido adiposo periepididimal (peso relativo do TA) e peso relativo do músculo sóleo (peso relativo do músculo sóleo) expressos em g de tecido/g de peso corpóreo; constante de decaimento da glicemia (kITT) expressa em percentual de decaimento da glicemia por minuto. Valores expressos como média \pm EPM ( $n=7$ a 10 animais por grupo). Símbolos estatísticos: ${ }^{*} P<0,05$ vs. $C S,{ }^{*} P<0,001$ vs. $C S$, ${ }^{*} P<0,01$ vs. $C E, P<0,001$ vs. $C E, P<0,05$ vs. $0 S$, ${ }_{2 \&} \mathrm{P}<0,001$ vs. OS. Grupos experimentais: controle sedentário (CS), controle exercitado (CE), obeso sedentário (OS) e obeso exercitado (OE). 
aumento de aproximadamente $33 \%$ no conteúdo de RNAm desse gene em relação ao grupo OS.

$\mathrm{Na}$ figura 3, é apresentado o conteúdo de proteína GLUT4 expresso por grama de tecido. Embora não se observe diferença estatística entre os grupos, houve uma importante redução de aproximadamente $30 \%$ no grupo OS comparado aos demais grupos, o que se correlacionou com o conteúdo de RNAm. Já o grupo exercitado OE apresentou aumento de $36 \%$ no conteúdo de proteína GLUT4 no músculo sóleo em relação

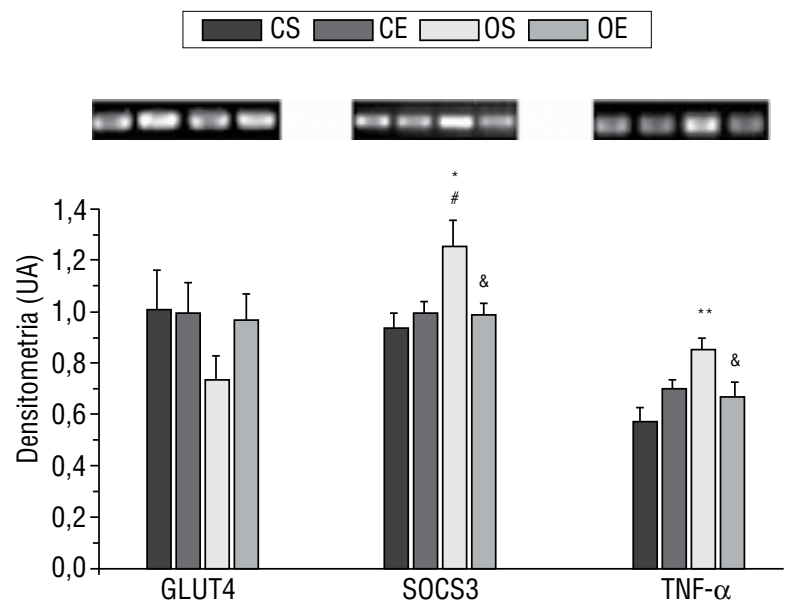

Figura 2. Gráfico representativo do conteúdo de RNAm do GLUT4, Socs3e TNF- $\alpha$ corrigidos pelo RNAm de beta-actina obtidos em ensaios de RT-PCR no tecido muscular solear dos grupos controle (CS), controle exercitado (CE), obeso sedentário (OS) e obeso exercitado (OE). Valores expressos em unidades arbitrárias (UA) como média \pm EPM ( $\mathrm{n}=7$ a 10 animais por grupo). ${ }^{*} P<0,05$ vs. CS, ${ }^{* *} P<0,001$ vs. CS, ${ }^{*} P<0,05$ vs. CE, \& $P<0,05$ vs. OS.

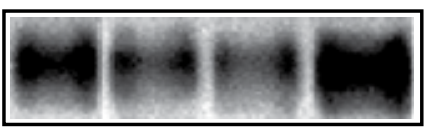

$45 \mathrm{kDa}$

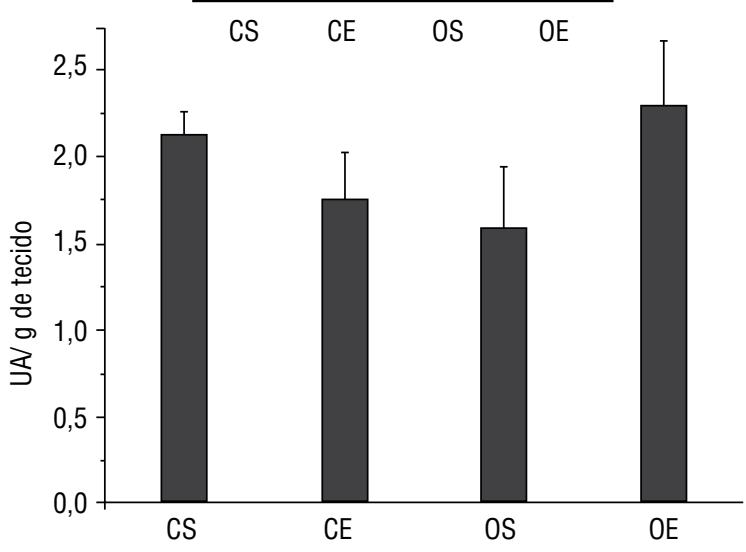

Figura 3. Gráfico representativo do conteúdo total de proteína GLUT4 por grama de tecido obtido em ensaio de Western Blotting. Grupos: controle sedentário (CS), controle exercitado (CE), obeso sedentário (OS) e obeso exercitado (OE). Valores expressos em unidades arbitrárias por grama de tecido (UA/g de tecido) como média \pm EPM ( $n=7$ a 10 animais por grupo em diferentes ensaios experimentais). aos animais OS, indicando provável melhora na expressão dessa proteína com a prática do exercício resistido.

\section{DISCUSSÃO}

Diversos estudos demonstraram que a ingestão de dieta hipercalórica está associada à resistência à insulina em humanos (27) e em animais (28). Tal alteração decorre do aumento expressivo da massa adiposa que induz uma elevação da produção e liberação de proteínas que prejudicam a sinalização da insulina e a expressão de transportadores de glicose em tecidos insulino-sensíveis (2).

No presente estudo, observou-se aumento expressivo no peso corpóreo e no ganho de massa adiposa periepididimal dos animais submetidos à dieta hiperlipídica em relação aos animais que receberam dieta-padrão. A partir desses resultados, pode-se inferir que a dieta hiperlipídica foi eficiente em gerar obesidade em ratos machos Wistar, a qual parece estar bem instalada na $12^{\circ}$ semana, a partir da qual não se observou aumento da massa corporal ao longo do desenvolvimento dos animais, mas se manteve maior até o final do estudo.

Diversos mecanismos adaptativos que regulam o metabolismo lipídico no músculo esquelético dão origem a condições metabólicas que parecem melhorar ou, por outro lado, piorar a ação da insulina (29). De acordo com essa afirmação, no presente estudo ocorreu redução na sensibilidade à insulina nos animais sedentários submetidos à dieta hiperlipídica durante 14 semanas (OS). Os eventos metabólicos que associam a exposição crônica à dieta hiperlipídica aos prejuízos na sinalização da insulina promovidos por serinas cinases, tais como a proteína cinase $\mathrm{C}$ (PKC), a proteína cinase ativada por mitogênio p-38 (MAPK p-38), subunidade catalítica $\mathrm{B}$ da proteína cinase IkB (IKK-B) e cinase c-Jun $\mathrm{N}$-terminal (JNK), ainda não são precisos. Mas uma teoria sugere que a resistência à insulina decorre de prejuízos da betaoxidação mitocondrial dos ácidos graxos e consequente acúmulo de metabólitos de lipídeos que ativam algumas cinases como a PKC e a JNK. Essas cinases, por sua vez, promovem transcrição de citocinas com efeitos pró-inflamatórios tal como o Tnf- $\alpha$ (30).

Goodpaster e Kelley (2002) verificaram aumento na sensibilidade à insulina em tecidos musculares em indivíduos treinados associado a níveis elevados de triacilglicerol (TAG), tal como encontrado na obesidade ou no diabetes melito (31). Da mesma forma, tanto o estoque de TAG quanto a sensibilidade à insulina são maiores em músculos com fibras predominantemente do 
tipo I do que nos que possuem mais fibras do tipo II (31). Dessa forma, a capacidade oxidativa muscular mostra-se melhor preditor da sensibilidade à insulina do que o conteúdo de TAG (32).

Estudos em animais roedores têm mostrado que a estimulação elétrica em músculos isolados, com pulsos de baixa frequência, por períodos prolongados (mimetizando treinamento aeróbio) (33), ou de alta frequência, por curtos períodos (mimetizando treinamento anaeróbio) (34), ativa seletivamente cascatas de sinalização associadas à biogênese mitocondrial, como a proteína cinase ativada por AMP (AMPK).

Dessa forma, pode-se inferir que a melhora da sensibilidade à insulina nos animais exercitados submetidos à dieta hiperlipídica do presente estudo provavelmente esteja associada, em parte, à melhora da capacidade oxidativa muscular.

Yaspelkis e cols. (35) observaram que os componentes da via pró-inflamatória são ativados em músculos esqueléticos de animais alimentados com dieta hipercalórica. Em concordância com essas observações, os achados do presente estudo mostram que a expressão de RNAm de Socs3 e Tnf- $\alpha$ aumentou em músculo esquelético oxidativo de ratos submetidos à dieta hiperlipídica $(\mathrm{OS})$ de maneira significativa.

Uma das vias pela qual o Tnf- $\alpha$ induz a resistência à insulina é o estímulo da lipólise no tecido adiposo, gerando aumento da concentração plasmática de ácidos graxos livres, que eventualmente contribui para o desenvolvimento desse fenótipo resistente à insulina (36). Além disso, o Tnf- $\alpha$ pode inibir o estímulo da insulina por meio da fosforilação do substrato do receptor de insulina (IRS-1) em serina (7). Adicionalmente, os efeitos da proteína SOCS3 na sensibilidade à insulina decorrem da sua colocalização nas subunidades beta do receptor de insulina (IR- $\beta$ ) e IRS- 1 , que resulta no impedimento da interação do IRS-1 com as IR- $\beta$, ocorrendo redução da atividade da PI3-kinase (9).

Os mecanismos moleculares que induzem a expressão da proteína SOCS3 em resposta à dieta hiperlipídica ainda não foram completamente esclarecidos. Normalmente, a transcrição de SOCS3 por meio de citocinas é induzida por meio da ativação dos fatores de transcrição da família de proteína ativadora da transcrição e sinalização da transdução (STAT) (37).

Recentemente, estudos mostraram o efeito do exercício físico aeróbio agudo (38) ou crônico (15) na modulação de marcadores inflamatórios. Rosa Neto e cols. (2009) observaram melhora da relação IL-10/
Tnf- $\alpha$ em tecidos musculares esqueléticos de ratos Wistar submetidos a uma sessão aguda de exercício físico exaustivo (38). E Yaspelkis e cols. observaram redução de RNAm de SOCS3 associado ao aumento de proteínas envolvidas na cascata de sinalização de insulina de animais obesos exercitados (15).

Estudos relacionados à modulação de citocinas no tecido muscular em resposta ao treinamento resistido ainda é escasso na literatura. Recentemente, Karagounis e cols. (2010) mostraram que o TR realizado por intervalos de 48 horas entre cada sessão promove redução do conteúdo de Tnf- $\alpha$ no quadríceps de ratos treinados a $75 \%$ da RM após 24 e 48 horas da quinta sessão de treinamento (39). No entanto, os efeitos do treinamento resistido sobre a expressão de SOCS3 muscular ainda não foram elucidados.

No presente estudo, a redução da expressão de citocinas pró-inflamatórias no músculo solear foi acompanhada pela melhora da sensibilidade à insulina periférica nos animais submetidos ao TR e à dieta hiperlipídica. Essa resposta ao treinamento resistido, provavelmente, pode ter sido promovida por adaptações positivas na capacidade oxidativa do músculo sóleo e, dessa forma, pode ter aumentado a metabolização de lipídeos, que, por sua vez, causa redução de fatores de transcrição de citocinas pró-inflamatórias, melhorando a sensibilidade à insulina (30). Porém, não se pode descartar o fato de que, no presente estudo, o tecido avaliado foi o músculo solear e que o TR pode, adicionalmente, surtir efeitos anti-inflamatórios em outros órgãos, tais como o tecido adiposo, o hipotálamo e o fígado (14). Adicionalmente, houve importante redução de massa adiposa periepididimal no grupo OE. Portanto, considerando que a avaliação da sensibilidade à insulina por meio do kITT não reflete apenas a ação do hormônio na musculatura, pode-se sugerir que a melhora da sensibilidade à insulina em resposta ao TR também pode ter ocorrido como consequência da redução de gordura corporal, bem como da melhora do quadro inflamatório em tecidos não musculares, como hepático e hipotalâmico, os quais não foram avaliados no presente estudo.

A expressão da proteína GLUT4, tal como a translocação para a membrana plasmática induzida por estímulo de insulina, é reduzida pela dieta de alto teor de gordura $(28,29)$. Contrariamente a essas observações, no presente estudo, a dieta hiperlipídica não surtiu efeito significante na expressão de RNAm de GLUT4 nem no conteúdo proteico, porém se observou importante tendência à redução $(30 \%)$ no grupo OS, quando comparado ao CS. Esse achado foi similar ao encontrado 
por Brandt e cols. (2010), no qual não houve alterações do conteúdo proteico da proteína transportadora de glicose no músculo gastrocnêmio de ratos submetidos à dieta hipercalórica (40).

Embora vários estudos mostrem aumento no conteúdo de GLUT4 após treinamento aeróbio, inesperadamente, neste modelo de treinamento, não ocorreu aumento significativo de proteína GLUT4, porém se observou forte tendência a um aumento apenas nos animais obesos treinados. Isso sugere que a eficiência na redução da massa adiposa após seis semanas de treinamento resistido foi o suficiente para ativar mecanismos que podem contribuir para melhora da sensibilidade à insulina e que não se reflete em conteúdo de transportador de glicose, tais como a ativação da AMPK, que, por sua vez, aumenta a captação de glicose e a redução da expressão de citocinas pró-inflamatórias, como evidenciado no presente estudo.

Além disso, a expressão de GLUT4 no músculo sóleo pouco se correlacionou com a sensibilidade à insulina, no presente estudo. Nesse aspecto, duas considerações são necessárias: primeiramente, o kITT não reflete apenas a sensibilidade à insulina no tecido muscular, como já mencionado anteriormente, e um segundo aspecto é o fato de que a utilização de anticorpos fosforilados como pIR, pIRSı e pAkt, bem como a avaliação de expressão de proteína GLUT4 em fração de membranas celulares, inclusive após estímulo por exercício ou insulínico, é a metodologia mais adequada para avaliação da sensibilidade à insulina nesse tecido (40). No presente estudo, foi avaliada a expressão de proteína GLUT4 em fração de membranas totais e, portanto, pode ter sido uma limitação em relação à observação dessa correlação.

Apesar dessas considerações, de maneira geral, em relação à modulação da expressão de GLUT4 na obesidade e no treinamento físico, observou-se estreita correlação entre conteúdos de RNAm e de proteína GLUT4, evidenciando regulação transcricional do gene dessa proteína nos modelos estudados.

Portanto, a dieta hiperlipídica foi eficiente para promover aumento da expressão de citocinas pró-inflamatórias locais, representadas pela SOCS3 e pelo Tnf- $\alpha$, somada à redução da sensibilidade à insulina. E o treinamento resistido foi eficiente para promover redução da expressão dos marcadores inflamatórios locais e adequação na sensibilidade à insulina, com retorno a valores próximos dos animais dos grupos controles.
Conclui-se, portanto, que a dieta hiperlipídica induz obesidade com ganho da massa adiposa e aumento de RNAm de marcadores inflamatórios na musculatura oxidativa e que o treinamento resistido nos animais obesos é eficaz para reverter as alterações tanto na expressão de RNAm de Socs3 e Tnf- $\alpha$ quanto na sensibilidade à insulina, o que não envolve modulação do conteúdo de RNAm e de proteína GLUT4.

Agradecimentos: Ao Prof. Dr. Luiz Carlos Vanderlei Marques e ao Prof. Dr. José Carlos Silva Camargo Filho, pela disponibilidade na utilização do biotério na Faculdade de Ciências e Tecnologia (FCT-Unesp), bem como à Fundação de Amparo à Pesquisa do Estado de São Paulo (Fapesp) 2004/10130-0; 2008/112634; 2009/01965-4, pelo apoio financeiro.

Declaração: os autores declaram não haver conflitos de interesse científico neste estudo.

\section{REFERÊNCIAS}

1. Ribeiro Filho FF, Mariosa LS, Ferreira SRG, Zanella MT. Gordura visceral e síndrome metabólica: mais que uma simples associação. Arq Bras Endocrinol Metabol. 2006;50(2):230-8.

2. Seraphim PM, Nunes MT, Machado UF. GLUT4 protein expression in obese and lean 12-month-old rats: insights from different types of data analysis. Braz J Med Biol Res. 2001;34:1353-62.

3. Valerio A, Cardile A, Cozzi V, Bracale R, Tedesco L, Pisconti A, et al.TNF-alpha downregulates iNOS expression and mitochondrial biogenesis in fat and muscle of obese rodents. J Clin Invest. 2006;116(10):2791-8.

4. Zentella A, Manogue K, Cerami A. Cachectin/TNF $\alpha$-mediated lactate production in cultured myocytes is linked to activation of a futile substrate cycle. Cytokine. 1993;5:436-47.

5. Furnsinn C, Neschen S, Wagner O, Roden M, Bisschop M, WaldhäusI W. Acute and chronic exposure to tumor necrosis factor-a fails to affect insulin-stimulated glucose metabolism of isolated rat soleus muscle. Endocrinology. 1997;138(7):2674-9.

6. De Blaauw I, Eggermont AM, Deutz NE, De Vries M, Buurman WA, Von Meyenfeldt MF. TNF- $\alpha$ has no direct in vivo metabolic effect on human muscle. Int J Cancer. 1997;71(2):148-54.

7. De Alvaro C, Teruel T, Hernandez R, Lorenzo M. Tumor necrosis factor alpha produces insulin resistance in skeletal muscle by activation of inhibitor kappaB kinase in a p38 MAPKdependent manner. J Biol Chem. 2004;279(17):17070-8.

8. AlexanderWS, Hilton DJ.The role of suppressors of cytokine signaling (SOCS) proteins in regulation of the immune response. Ann Rev Immunol. 2004;22(1):503-29.

9. Emanuelli B, Peraldi P, Filloux C, Sawka-Verhelle D, Hilton D, Van Obberghen E. SOCS3 is an insulin-induced negative regulator of insulin signaling. J Biol Chem. 2000;275(21):15985-91.

10. Bastard JP, Maachi M, Lagathu C, Kim MJ, Caron M, Vidal H, et al. Recent advances in the relationship between obesity, inflammation, and insulin resistance. Eur Cytokine Netw. 2006;17:4-12.

11. Glass DJ. Skeletal muscle hypertrophy and atrophy signaling pathways. Int J Biochem Cell Biol. 2005;37:1974-84.

12. Hotamisligil GS. Inflammation and metabolic disorders. Nature. 2006;444:860-7.

13. Nicklas BJ, Ambrosius W, Messier SP, Miller GD, Penninx BWJH, Loeser RF, et al. Diet-induced weight loss, exercise, and chronic inflammation in older, obese adults: a randomized controlled clinical trial. Am J Clin Nutr. 2004;79(4):544-51. 
14. Beavers KM, BrinkleyTE, Nicklas BJ. Effect of exercise training on chronic inflammation. Clin Chim Acta. 2010;411:785-93.

15. Yaspelkis BB, Kvasha I, Lessard S, Rivas D, Hawley J. Aerobic training reverses high-fat diet-induced pro-inflammatory signalling in rat skeletal muscle. Eur J App Physiol. 2010;110(4):779-88.

16. Bloomer RJ. The role of nutritional supplements in the prevention and treatment of resistance exercise-induced skeletal muscle injury. Sports Med. 2007; 37:519-32.

17. Coffey VG, Hawley JA. The molecular bases of training adaptation. Sports Med. 2007;37:737-63.

18. Steensberg A, Keller C, Starkie RL, OsadaT, Febbraio MA, Pedersen BK. IL-6 and TNF- $\alpha$ expression in, and release from, contracting human skeletal muscle. Am J Physiol Endocrinol Metab. 2002;283:E1272-8.

19. Greiwe JS, Cheng B, Rubin DC, Yarasheski KE, Semenkovich CF. Resistance exercise decreases skeletal muscle tumor necrosis factor a in frail elderly humans. FASEB J. 2002;15:475-82.

20. Calle MC, Fernandez ML, Kraemer WJ, Volk BM, Kupchak B, Volek JS. Resistance training improves the inflammatory response to an acute resistance exercise bout in healthy young adults. FASEB J. 2010;24:743-2.

21. Stewart LK, Flynn MG, Campbell WW, Craig BA, Robinson JP, Timmerman $\mathrm{KL}$, et al. The influence of exercise training on inflammatory cytokines and C-reactive protein. Med Sci Sports Exerc. 2007;39:1714-9.

22. De Salles BF, Simão R, Fleck SJ, Dias I, Kraemer-Aguiar LG, Bouskela $\mathrm{E}$. Effects of resistance training on cytokines. Int $\mathrm{J}$ Sports Med. 2010;31:441-50.

23. Nieman DC, Davis JM, Brown VA, Henson DA, Dumke CL, Utter $A C$, et al. Influence of carbohydrate ingestion on immune changes after $2 \mathrm{~h}$ of intensive resistance training. J Appl Physiol. 2004;96:1292-8.

24. Kirwan JP, Del Aguila LF. Insulin signalling, exercise and cellular integrity. Biochem Soc Trans. 2003;31:1281-5.

25. Lamas O, Martínez JA, Marti A. Energy restriction restores the impaired immune response in overweight (cafeteria) rats. J Nutr Biochem. 2004;15(7):418-25.

26. Tamaki T, Uchiyama S, Nakano S. A weight-lifting exercise model for inducing hypertrophy in the hindlimb muscles of rats. Med Sci Sports Exerc. 1992;24(8):881-6.

27. Boden $\mathrm{G}$. Role of fatty acids in the pathogenesis of insulin resistance and NIDDM. Diabetes. 1997;46(1):3-10.

28. Lessard SJ, Rivas DA, Chen Z-P, Bonen A, Febbraio MA, Reeder DW, et al. Tissue-specific effects of rosiglitazone and exercise in the treatment of lipid-induced insulin resistance. Diabetes. 2007;56(7):1856-64.
29. Yaspelkis BB, Lessard SJ, Reeder DW, Limon JJ, Saito M, Rivas $D A$, et al. Exercise reverses high-fat diet-induced impairments on compartmentalization and activation of components of the insulin-signaling cascade in skeletal muscle. Am J Physiol Endocrinol Metab. 2007;293(4):941-9.

30. Silveira LR, Fiamoncini J, Hirabara SM, Procópio J, Cambiaghi TD, Pinheiro CHJ, et al. Updating the effects of fatty acids on skeletal muscle. J Cell Physiol. 2008;217:1-12.

31. Goodpaster BH, Kelley DE. Skeletal muscle trygliceride: marker or mediator of obesity-induced insulin resistance in type 2 diabetes mellitus? Curr Diab Rep. 2002; 2:216-22.

32. Bruce CR, Anderson MJ, Carey Al, Newman DG, Bonen A, Kriketos AD. Muscle oxidative capacity is a better predictor of insulin sensitivity than lipid status. J Clin Endocrinol Metab. 2003;88:5444-51.

33. Atherton PJ, Babraj J, Smith K, Singh J, Rennie MJ, Wackerhage $\mathrm{H}$. Selective activation of AMPK-PGC-1alpha or PKB-TSC2-mTOR signaling can explain specific adaptive responses to endurance or resistance training-like electrical muscle stimulation. FASEB J. 2005; 19:786-8.

34. Gibala M. Molecular responses to high-intensity interval exercise. Appl Physiol Nutr Metab. 2009;34:428-32.

35. Yaspelkis BB, Kvasha IA, Figueroa TY. High-fat feeding increases insulin receptor and IRS-1 coimmunoprecipitation with SOCS3, IKKalpha/beta phosphorylation and decreases PI-3 kinase activity in muscle. Am J Physiol Regul Integr Comp Physiol. 2009;296(6):1709-15.

36. Popa C, Netea MG, Van Riel PLCM, Van der Meer JWM, Stalenhoef AFH. The role of TNF- $\alpha$ in chronic inflammatory conditions, intermediary metabolism, and cardiovascular risk. J Lipid Res. 2007;48:751-62.

37. Emanuelli B, Peraldi P, Filloux C, Chavey C, Freidinger K, Hilton DJ, et al. SOCS3 inhibits insulin signaling and is up-regulated in response to tumor necrosis factor-alpha in the adipose tissue of obese mice. J Biol Chem. 2001;276(51):47944-9.

38. Rosa Neto JC, Lira FS, Oyama LM, Zanchi NE, Yamashita AS, Batista Jr ML, et al. Exhaustive exercise causes an anti-inflammatory effect in skeletal muscle and a pro-inflammatory effect in adipose tissue in rats. Eur J Appl Physiol. 2009;106:697-704.

39. Karagounis LG, Yaspelkis BB, Reeder DW, Lancaster GI, Hawley JA, Coffey VG. Contraction-induced changes in TNF- $\alpha$ and Akt-mediated signalling are associated with increased myofibrillar protein in rat skeletal muscle. Eur J Appl Physiol. 2010;109:839-48.

40. Brandt N, De Bock K, Richter EA, Hespel P. Cafeteria diet-induced insulin resistance is not associated with decreased insulin signaling or AMPK activity and is alleviated by physical training in rats. Am J Physiol Endocrinol Metab. 2010;299(2):E215-24. 